\title{
Pencegahan Tuberkulosis Paru dalam Keluarga: Kajian Literatur
}

\author{
Sri Ayu Rahayu S. Paneo \\ Mahasiswa Magister Keperawatan Komunitas, Fakultas Ilmu Keperawatan, Universitas Indonesia; \\ sri.ayu71@ui.ac.id (koresponden) \\ Astuti Yuni Nursasi \\ Departemen Keperawatan Komunitas, Fakultas Ilmu Keperawatan, Universitas Indonesia
}

\begin{abstract}
Tuberculosis is an infectious disease caused by Mycobaterium Tuberculosis and transmitted through sputum sprinkling. Tuberculosis disease have increase every year which is a contributor of mortality in the world. Transmission of tuberculosis is growing and resulting in increased transmission in the family and community environment. Families who are in contact with tuberculosis sufferers being a vulnerable populations to be infected. Various types of efforts are needed to prevent tuberculosis transmission. This article aims to explore the prevention of tuberculosis in the family. The literature review came from articles obtained from Pubmed, ScienceDirect, Wiley, SAGE Publications, Google Scholar and EBSCOHost since 2010-2019. The results of the study found that the prevention of transmission infection in the family were; provide immunization to babies, fulfill adequate nutrition for sufferers and family members, modify the home environment and control tuberculosis patients to get regular treatment. The role of the family becomes very important in prevention of transmission and the role of professional community nurses is also needed in order to strengthen aspects of health care services for tuberculosis sufferers. Family and nurse collaboration is a matter that needs to be increased simultaneously for optimal community health.
\end{abstract}

Keywords: prevention of transmission; nursing; family roles; tuberculosis treatment

\begin{abstract}
ABSTRAK
Penyakit tuberkulosis adalah penyakit menular yang disebabkan oleh bakteri Mycobaterium Tuberculosis dan ditularkan melalui percikan dahak. Penyakit ini terus mengalami peningkatan di tiap tahunnya dimana merupakan penyumbang kematian di dunia. Penularan penyakit ini semakin berkembang dan mengakibatkan pada peningkatan penularan di lingkungan keluarga dan masyarakat. Keluarga yang sekontak dengan penderita tuberkulosis menjadi populasi yang paling rentan terinfeksi sehingga dibutuhkan berbagai macam upaya pencegahan penularan tuberkulosis. Artikel ini bertujuan untuk menggali bentuk pencegahan tuberkulosis dalam keluarga. Telaah literatur berasal dari artikel yang didapatkan dari Pubmed, ScienceDirect, Wiley, SAGE Publications, Google Scholar dan EBSCOHost sejak tahun 2010-2019. Hasil kajian yang didapatkan ditemukan bahwa bentuk pencegahan yang dapat dilakukan dalam memutus rantai penularan infeksi dalam keluarga yang terdiri dari; memberikan imunisasi pada bayi, pemenuhan nutrisi yang adekuat bagi penderita maupun anggota keluarga, modifikasi lingkungan rumah serta kontrol penderita tuberkulosis agar berobat dengan teratur. Peran keluarga menjadi sangat penting dalam upaya memutus rantai penularan dan peran perawat komunitas yang professional juga dibutuhkan dalam rangka menguatkan aspek layanan perawatan kesehatan untuk penderita tuberkulosis. Kerjasama keluarga dan perawat menjadi hal yang perlu ditingkatkan secara simultan demi kesehatan masyarakat yang optimal.
\end{abstract}

Kata kunci: pencegahan penularan; keperawatan; peran keluarga; pengobatan tuberkulosis

\section{PENDAHULUAN}

\section{Latar Belakang}

Universal Health Coverage (UHC) adalah trend pembangunan kesehatan yang sedang digencarkan khususnya di Indonesia. UHC ini berkaitan dengan indeks pembangunan manusia dimana keduanya merupakan hal yang dapat dinilai sebagai indikator mutu berkualitasnya pelayanan kesehatan di Indonesia ${ }^{(1)}$. Salah satu indikator tersebut dapat diketahui melalui pencapaian Indikator Keluarga Sehat (IKS) dimana aspek kesehatan keluarga menjadi acuan mendasar dalam sebuah pembangunan pelayanan kesehatan. Keberhasilan dari pembinaan kesehatan di keluarga menjadi kunci dari pembinaan kesehatan di masyarakat ${ }^{(2),(3)}$. Salah satu IKS adalah keluarga dengan penyakit menular Tuberculosis (TBC) berobat sesuai dengan standar ${ }^{(2)}$.

TBC adalah salah satu penyakit menular yang terus mengalami peningkatan di tiap tahun. Setidaknya ditemukan lebih dari 9 juta penderita TBC di tiap tahun dimana 1 juta diantaranya adalah anak-anak. Lebih dari 3 juta penderita tidak dapat diketahui penyebabnya yang berakibat pada meningkatnya penularan TBC di 
lingkungan keluarga maupun masyarakat ${ }^{(4)}$. Penularan TBC dalam keluarga disebabkan oleh kontak serumah dengan pasien. Sebuah studi menunjukkan dari 100 kontak yang tinggal dengan pasien TBC terhitung ditemukan 7 keluarga yang teridentifikasi memiliki penyakit TBC yang ditegakkan dengan pemeriksaan bakteriologis $^{(5)}$.

Sumber penularan utama yang ditemukan pada anak anak biasanya terjadi di rumah tangga dimana penularan yang paling umum disebabkan oleh kontak dengan anggota keluarga dewasa yang mengidap $\mathrm{TBC}^{(6),(7)}$. Sebuah studi di Myanmar menyatakan bahwa dari 174 kontak rumah tangga, persentase kasus TB yang terdeteksi melalui kontak rumah tangga adalah $13,8 \%$. Terdapat $12,2 \%$ kasus TB positif yang ditemukan dengan usia $>15$ tahun dan sebanyak $16,9 \%$ yang berusia $<15$ tahun memiliki tanda-tanda klinis dan gejala TB. Faktor risiko di antara kontak rumah tangga untuk TB adalah keluarga terdekat yang menjadi Pengawas Menelan Obat (PMO), perokok aktif dan pasif, dan peningkatan gaya hidup keluarga seperti minum alkohol ${ }^{(8)}$.

Keluarga adalah popupaling rentan untuk tertularnya penyakit TBC sehingga perlu dilakukan pencegahan agar tidak terjadi penularan ${ }^{(6),(9)}$. Tujuan kajian ini adalah untuk mengetahui bentuk bentuk pencegahan yang dapat dilakukan keluarga dalam memutuskan rantai infeksi penularan TBC karena kontak serumah dengan penderita TBC.

\section{METODE}

Metode penulisan artikel literature review ini melalui database online Pubmed, ScienceDirect, Wiley, SAGE Publications, Google Scholar dan EBSCOhost. Literatur dibatasi dari tahun 2010-2019 dengan kata kunci "family prevention of Tuberculosis","household TBC prevention" dan "family with TBC". Sebanyak 10 artikel didapatkan pada studi literatur ini.

\section{HASIL}

\section{Pencegahan Penularan TBC Kontak Serumah dengan Penderita Melalui Imunisasi}

Penyakit TBC adalah salah satu penyakit yang dapat menularkan ke semua orang terutama pada bayi dan anak-anak. Sebuah studi menyebutkan bahwa bentuk pencegahan yang aman dan handal dapat dilakukan dengan aktif memberikan imunisasi ${ }^{(10)}$. Imunisasi terbukti mencegah bentuk TBC pada masa kanak-kanak dan dewasa. Sebuah penelitian retrospektif yang membandingkan tingkat TBC paru dalam kelompok yang divaksinasi saat lahir dengan tingkat populasi. Kemanjuran vaksin ditemukan menjadi 39\% (95\% CI, 9\% -58\%) 15 hingga 20 tahun setelah vaksinasi yang berarti vaksin menunjukkan perlindungan hingga dewasa awal ${ }^{(11)}$. Hal ini berarti pemberian imunisasi menjadi landasan pencegahan TBC dalam pengaturan dengan risiko yang signifikan untuk infeksi dan penyakit $\mathrm{TBC}^{(12)}$.

\section{Pencegahan Penularan Melalui Peningkatan Nutrisi Penderita TBC}

Penyakit TBC sebagai penyakit yang memberikan sumbangsih kematian kedua di dunia memiliki situasi rumit yang memperburuk penyebarannya. Kondisi kekurangan nutrisi mampu meningkatkan angka mortalitas pasien TBC. Hal ini berkaitan dengan kemampuan nutrisi dalam pemulihan sel sel baru yang memiliki peran dalam proses pembersihan dahak lebih cepat. Selain itu, nutrisi yang baik berbanding lurus dengan penambahan berat badan yang terbukti mampu mengurangi kejadian penularan $\mathrm{TBC}^{(13)}$.

Sebuah studi yang dilakukan pada 160 pasien TBC aktif menunjukkan terdapat korelasi yang signfikan antara pengetahuan dan kemampuan perawatan diri dalam peningkatan asupan makanan. Studi ini menemukan bahwa status gizi yang buruk lebih umum ditemukan pada pasien TBC aktif daripada yang tidak menderita TBC. Kondisi nutrisi memberikan dampak yang berarti bagi perkembangan penderita. Gejala penderita yang tidak memiliki nafsu makan semakin memperberat ketahanan tubuh penderita. Oleh karena itu, penting untuk memberikan pasien TBC makanan yang bervariasi dan sehat agar mengurangi resiko penularan bagi anggota keluarga yang lain ${ }^{(14)}$.

\section{Pencegahan Penularan Infeksi TBC Melalui Modifikasi Lingkungan Rumah}

TBC adalah penyakit menular yang ditularkan melalui udara, dimana faktor penyebab yang berkontribusi pada pengembangan bakteri TBC adalah faktor endogen dan eksogen. Sebuah penelitian yang dilakukan untuk mengekplorasi faktor lingkungan yang mampu mempengaruhi resiko perkembangan penyakit TBC memeroleh hasil dimana kondisi lingkungan rumah yang lembab, perumahan yang penuh dan sesak disertai dengan ventilasi yang buruk memiliki potensi peningkatan paparan bakteri Mycobacterium Tuberculosis dan perkembangan penyakit lainnya ${ }^{(15)}$.

Hal ini didukung oleh penelitian lain yang menyatakan bahwa lingkungan rumah tangga yang terkontaminasi meningkatkan risiko TBC di India. Kondisi lingkungan rumah tangga seperti mengumpulnya asap di dalam rumah, jenis bahan bakar memasak, dapur terpisah, jumlah orang yang tidur di kamar lebih dari kapasitas maksimal, berbagi toilet dan air minum dengan rumah tangga lain ${ }^{(16)}$. Sebuah penelitian lain 
mengungkapkan kondisi lingkungan rumah yang memenuhi syarat bagi penderita TBC adalah terdapatnya ventilasi rumah yang sesuai dengan kapasitas ruangan, pencahayaan alami, suhu dan kelembaban yang sesuai standar serta jumlah penghuni rumah yang tidak padat ${ }^{(17)}$. Sehingga penting bagi setiap anggota keluarga untuk melakukan modifikasi lingkungan rumah yang ramah agar terbebas dari resiko penularan infeksi TBC.

\section{Pencegahan Penularan Melalui Kontrol Kepatuhan Pengobatan TBC oleh Keluarga}

Pengobatan TBC yang teratur mampu menurunkan kemampuan bakteri dalam menginfeksi kepada orang lain, sehingga resiko penularan akan semakin menurun ${ }^{(18)}$. Sehingga dalam rangka penguatan kepatuhan pasien TBC mengkonsumsi obat dibutuhkan dukungan penuh dari anggota keluarga agar kemampuan pasien melawan TBC semakin meningkat. Sebuah studi yang dilakukan di Jayapura, Indonesia menyatakan bahwa faktor yang mempengaruhi ketidakpatuhan konsumsi obat pasien TBC tidak hanya disebabkan oleh akses menuju layanan kesehatan yang terbatas tapi juga disebabkan oleh keterbatasan pengetahuan tentang pengobatan TBC dan pengetahuan tentang penyakit ${ }^{(19)}$.

Hal ini didukung oleh penelitian lain yang menyatakan bahwa ketidakpatuhan pengobatan disebabkan oleh stigma tentang penyakit sehingga dibutuhkan pendukung sosial seperti keluarga untuk meningkatkan perilaku sehat pasien $\mathrm{TBC}^{(20)}$. Bentuk dukungan yang diberikan oleh keluarga dalam mengontrol kepatuhan pengobatan dapat berupa memberikan perhatian, membantu kehidupan sehari-hari, menemani pasien menuju pelayanan kesehatan, dan senantiasa mengingatkan jadwal pengobatan ${ }^{(21)}$.

\section{PEMBAHASAN}

\section{Strategi Peningkatan Pengetahuan dan Perilaku Sehat untuk Keluarga dan Penderita TBC}

Berbagai metode pencegahan penyakit, pendidikan kesehatan dan program kesadaran kesehatan menjadi sangat penting khusunya pada generasi muda dalam memerangi TBC. Kondisi ini mampu menghasilkan pemberdayaan keluarga yang berkaitan dengan aspek manajemen penyakit dimana memungkinkan keluarga dan penderita mampu meningkatkan kepatuhan pengobatan sehingga resistensi terhadap obat dapat dikurangi ${ }^{(22),(23)}$.

Strategi kesadaran kesehatan berupa Structured Tuberculosis Awareness Strategy (STAS) yang berfokus pada anggota keluarga penderita TBC yang berada di daerah kumuh yang diketahui memiliki pengetahuan dan perilaku buruk dalam penanganan TBC. Intervensi kesadaran ini dikemas dalam bentuk Kampanye, Informasi dan Edukasi (KIE) yang dilakukan selama sebulan di 100 rumah tangga pada seluruh anggota keluarga yang ada di rumah. Hasil penelitian ini menunjukkan intervensi ini berhasil meningkatkan memberikan kesadaran keluarga tentang TBC termasuk gejalanya, diagnosis, pengobatannya dan layanan Revised National TB Control Program. Kesadaran kesehatan yang terjadi pada keluarga mengalami peningkatan hingga di atas $90 \%$ kecuali pada komponen pengetahuan tentang penularan TBC dan informasi fasilitas kesehatan gratis ${ }^{(24)}$.

Strategi kesadaran kesehatan ini dirasa mampu memberikan pengetahuan yang berkualitas bagi penderita, selain untuk mengurangi angka kekambuhan juga mampu memutus rantai penularan infeksi yang terjadi di keluarga. Sebuah studi lain yang dilakukan pada Anak Usia Sekolah (AUS) dalam rangka peningkatan pengetahuan dan kesadaran tentang penyakit TBC. Strategi ini terbukti mampu memberkan efek jangka panjang pada penyebaran informasi tentang TBC di keluarga dan masyarakat umum. Anak-anak yang mendapatkan pendidikan lebih tinggi menjadi sumber dan perluasan informasi kesehatan bagi masyarakat yang tidak terjangkau oleh metode konvesional promosi kesehatan ${ }^{(23)}$.

\section{Potensi Pencegahan Tuberkulosis Berbasis Keluarga di Indonesia}

Beban ekonomi TBC di Indonesia sangat tinggi. Proses deteksi dan penanganan yang lebih dini akan menghasilkan tidak hanya pengurangan besar dalam penderitaan tetapi juga penghematan ekonomi bagi masyarakat. Beban ekonomi sebagian besar dipengaruhi oleh kematian prematur, penurunan produktivitas karena kesakitan, serta biaya medis dan non medis yang harus dikeluarkan oleh keluarga. Total beban ekonomi TB di Indonesia mencapai 6.9 Milyar USD atau 99 Triliyun Rupiah ${ }^{(25)}$.

Kondisi ini menjadi alarm untuk peningkatan kualitas pelayanan yang ada di Indonesia terlebih dengan menekankan pada upaya promotif dan preventif yang ada di lingkungan keluarga. Program Indonesia Sehat Pendekatan Keluarga (PIS-PK) tampaknya menjadi sebuah program yang memberikan penagruh positif dalam hal peningkatan pelayanan khususnya penyakit TBC untuk meningkatkan cakupan Universal Health Coverage $^{(2)}$. Hal ini sejalan dengan upaya yang dilaksanakan oleh pemerintah Brazil dimana dalam rangka menguatkan perawatan kesehatan dilakukan Family Health Strategy sebagai landasan utama dalam penguatan Primary Health Care dimana prioritas pelayanan yang diberikan berfokus pada aspek promotif dan preventif, pemulihan kesehatan secara integral dan berkelanjutan ${ }^{(26)}$.

\section{Peran Perawat Komunitas dalam Pengembangan Upaya Pencegahan Penularan TBC Berbasis Keluarga}

Perawat dapat menjadi tenaga kesehatan yang mampu menguatkan peran keluarga dalam pelayanan pencegahan penularan infeksi TBC. Kemampuan perawat dalam berinteraksi dengan tim, pasien dan keluarga 
pasien dengan kasih sayang dan komunikasi yang baik mampu menguatkan target pelayanan keperawatan yang paripurna bagi penderita TBC dan keluarga ${ }^{(27)}$. Peran perawat dalam pelaksanaan pelayanan Direct Observed Treatment Short Course (DOTS) disertai dengan pelayanan deteksi kontak rumah TBC dan skrining mangkir obat menjadi sebuah acuan dalam menguatkan layanan keperawatan berbasis keluarga ${ }^{(28)}$. Hal ini didukung sebuah penelitian menyebutkan bahwa layanan kesehatan pemberantasan penularan TBC terbukti lebih efektif apabila dalam pelaksanannya disertai strategi kesehatan yang melibatkan keluarga. Hal spesifik yang menjadi tolak ukur adalah kemampuan keluarga dalam mendeteksi dini penyakit TBC yang terjadi pada anggota keluarga yang lain ${ }^{(29)}$. Kelemahan pelayanan perawatan kesehatan bagi penderita TBC terletak pada sumber daya manusia yang berkualitas rendah dan mobilisasi sosial yang lemah, namun hal ini mampu diantisipasi dengan menjadikan keluarga sebagai mitra kerjasama dalam pengendalian penularan $\mathrm{TBC}^{(30)}$.

Kemampuan perawat dalam memberikan layanan yang prima disertai pengetahuan yang baik memberikan pengaruh pada kualitas layanan yang diberikan. Sebagai perawat yang berada dalam cakupan Primary Health Care (PHC) dibutuhkan perbaharuan para professional dimana perawat TBC harus memiliki kesadaran penuh akan pentingnya peran mereka dalam diagnosis, pencegahan, pengobatan, pedoman dan pengurangan akibat penularan infeksi penyakit $\mathrm{TBC}^{(31)}$.

\section{KESIMPULAN}

Keluarga adalah populasi yang memiliki resiko tinggi dan terbesar mengalami penularan terhadap penyakit TBC karena kontak rumah dengan pasien. Akan tetapi bersamaan dengan hal tersebut keluarga juga memegang peranan penting dalam upaya menurukan penularan infeksi TBC yang ada di rumah tangga dengan melakukan beberapa upaya pencegahan seperti meningkatkan cakupan imunisasi pada anak-anak, peningkatan nutrisi bagi pasien dan seluruh anggota keluarga, melakukan modifikasi lingkungan yang baik serta melakukan kontrol pengobatan TBC bagi pasien. Upaya yang dilakukan keluarga tidak akan berjalan sepenuhnya tanpa adanya bantuan dari berbagai pihak salah satunya perawat komunitas yang berperan langsung dalam pendekatan keluarga. Indonesia kini yang sedang menjalankan agenda nasional Program Indonesia Sehat Pendekatan Keluarga diharapkan dapat menjadi program penguatan tata laksana primer dalam rangka menurunkan angka kesakitan, kematian dan penularan penyakit TBC yang ada di masyarakat.

\section{DAFTAR PUSTAKA}

1. Agustina R, Dartanto T, Sitompul R, Susiloretni KA, Achadi EL, Taher A, et al. Review Universal health coverage in Indonesia : concept , progress , and challenges. Lancet J. 2018;6736(18):1-28.

2. Kemenkes RI. Program Indonesia Sehat dengan Pendekatan Keluarga. Jakarta; 2016.

3. Hudziak J, Ivanova MY. The Vermont Family Based Approach. Child Adolesc Psychiatry Clin NA [Internet]. 2016;25(2):167-78. Available from: http://dx.doi.org/10.1016/j.chc.2015.11.002

4. Keshavjee S, Dowdy D, Swaminathan S. Stopping the body count : a comprehensive approach to move towards zero tuberculosis deaths. Lancet [Internet]. 2015;386(10010):e46-7. Available from: http://dx.doi.org/10.1016/S0140-6736(15)00320-7

5. Beyanga M, Kidenya BR, Gerwing-adima L, Ochodo E, Mshana SE, Kasang C. Investigation of household contacts of pulmonary tuberculosis patients increases case detection in Mwanza City, Tanzania. BMC Infect Dis [Internet]. 2018;18(110):1-9. Available from: https://doi.org/10.1186/s12879-018-3036-6

6. Mcintosh AI, Doros G, Jones-lópez EC, Gaeddert M, Jenkins HE, Marques-rodrigues P, et al. Extensions to Bayesian generalized linear mixed effects models for household tuberculosis transmission. Stat Med. 2017;(March):1-11.

7. Triasih R, Robertson C, Duke T, Graham SM. Risk of infection and disease with Mycobacterium tuberculosis among children identified through prospective community- based contact screening in Indonesia. Trop Med Int Heal. 2015;20(6):737-43.

8. Htet KKK, Liabsuetrakul T, Thein S, Mcneil EB, Chongsuvivatwong V. Improving detection of tuberculosis among household contacts of index tuberculosis patients by an integrated approach in Myanmar: a cross-sectional study. BMC Infect Dis [Internet]. 2018;18(660):1-9. Available from: https://doi.org/10.1186/s12879-018-3586-7

9. Puma D V, Perez-Quılez O, Roure S, Martınez-Cuevas O, Bocanegra C, Feijoo-Cid M, et al. Risk of Active Tuberculosis among Index Case of Householders - A Long-Term Assessment after the Conventional Contacts Study. Public Health Nurs. 2016;34(2):112-7.

10. Muniyandi, Singh N. On the Move against Tuberculosis : Transforming the Fight-towards Elimination of Tuberculosis. J Health Manag. 2014;16(1):13-24.

11. Nguipdop-djomo P, Heldal E, Rodrigues LC, Abubakar I, Mangtani P. Duration of BCG protection against tuberculosis and change in eff ectiveness with time since vaccination in Norway: a retrospective population-based cohort study. Lancet Infect Dis [Internet]. 2015;3099(15):1-8. Available from: http://dx.doi.org/10.1016/S1473-3099(15)00400-4

12. Gijsel D De, Reyn CF Von. International Journal of Infectious Diseases A Breath of Fresh Air : BCG 
Prevents Adult Pulmonary Tuberculosis. Int J Infect Dis [Internet]. 2019;80:S6-8. Available from: https://doi.org/10.1016/j.ijid.2019.02.036

13. Semba RD, Darnton-hill I, Pee S De. Addressing tuberculosis in the context of malnutrition and HIV coinfection. Food Nutr (Roma) [Internet]. 2010;31(4):345-64. Available from: $10.1177 / 15648265100314 S 404$

14. Heydari A, Shadan MR, Miri A, Khoushabi F. The Effects of Health Belief Model ( HBM ) based on Health Education and food advised on the Promotion of Self-care Behaviors in Tuberculosis patients. Sch Res Libr [Internet]. 2017;9(5):60-72. Available from: www.scholarsresearchlibrary.com Scholars

15. Srivastava K, Kant S, Verma A. Role of Environmental factors in Transmission of Tuberculosis. Dyn Hum Heal [Internet]. 2015;2(4):1-8. Available from: http://journalofhealth.co.nz/?page_id=982

16. Singh SK, Kashyap GC, Puri P. Potential effect of household environment on prevalence of tuberculosis in India: evidence from the recent round of a cross-sectional survey. BMC Pulm Med [Internet]. 2018;18(66):1-10. Available from: medind.nic.in/ibr/t12/i4/ibrt12i4p224

17. Wanti, Solihah Q, Djapawiwi M. Relationship between House Condition and Tuberculosis Incidence in Timor Tengah Utara District. Int J Sci Basic Appl Res [Internet]. 2015;21(1):344-9. Available from: http://gssrr.org/index.php?journal=JournalOfBasicAndApplied

18. Ogari CO, Nyamache AK, Nonoh J, Amukoye E. Prevalence and detection of drug resistant mutations in Mycobacterium tuberculosis among drug naïve patients in Nairobi, Kenya. BMC Infect Dis [Internet]. 2019;19(279):1-8. Available from: https://doi.org/10.1186/s12879-019-3911-9

19. Ruru Y, Matasik M, Oktavian A, Senyorita R, Mirino Y. Factors associated with non-adherence during tuberculosis treatment among patients treated with DOTS strategy in Jayapura, Papua Province , Indonesia. Glob Health Action [Internet]. 2018;11:1-9. Available from: https://doi.org/10.1080/16549716.2018.1510592

20. Gebreweld FH, Kifle MM, Gebremicheal FE, Simel LL, Gezae MM, Ghebreyesus SS, et al. Factors influencing adherence to tuberculosis treatment in Asmara, Eritrea : a qualitative study. J Heal Popul Nutr. 2018;37(1):1-10.

21. Kaulagekar-nagarkar A, Dhake D, Jha P. Perspective Of Tuberculosis Patients On Family Support And Care In Rural Maharashtra. Indian J Tuberc [Internet]. 2012;59:224-30. Available from: medind.nic.in/ibr/t12/i4/ibrt12i4p224

22. Saranya P, Swathi S, Kousalya K, Praveen D. A Prospective Interventional Study of Knowledge , Attitude and Practice (KAP) Towards Tuberculosis Among Patients With Koch's Disease. Int J Pharm Pharm Sci. 2016;8(3):6-9.

23. Gopichandran V, Roy P, Sitaram A, John KR. Short Communication Impact of a Simple Educational Intervention on the Knowledge and Awareness of Tuberculosis among High School children in Vellore, India. Indian J Community Med. 2010;35(1):174-6.

24. Samal J, Dehury RK. Impact of a Structured Tuberculosis Awareness Strategy on the Knowledge and Behaviour of the Families in a Slum Area in Chhattisgarh , India. J Cinical Diagnostic Res. 2017;11(3):115.

25. Collins D, Hafidz F, Mustikawati D. The economic burden of tuberculosis in Indonesia. Int J Tuberc Lung Dis [Internet]. 2017;21(9):1041-8. Available from: http://dx.doi.org/10.5588/ijtld.16.0898

26. Sobrinho RAS, Souza AL de, Wysocki AD, Silva LMC da, Beraldo AA, Villa TCS. Primary Health Care Center Nurses ' Knowledge Regarding Tuberculosis. Cogitare Enfermia [Internet]. 2014;19(1):34-40. Available from: https://revistas.ufpr.br/cogitare/article/view\%0A/35930/22161

27. Rach V. How is the role of the tuberculosis nurse pivotal in the multidisciplinary team ? Br Student Dr J [Internet]. 2018;2(1):26-30. Available from: bsjd.org.uk

28. Mnisi SD, Peu MD, Meyer SM. Role of community nurses in the prevention of tuberculosis in the Tshwane Health District of Gauteng. Curationis J [Internet]. 2012;35(1):1-9. Available from: http://www.curationis.org.za

29. Cardozo-gonzales RI, Palha PF, Harter J, Alarcon E, Lima LM de, Tomberg JO. Evaluation of detection actions for tuberculosis cases in primary care. Rev Eletronica Enferm [Internet]. 2015;17(4):1-7. Available from: http://dx.doi.org/10.5216/ree.v17i4.32846

30. Sá LD De, Luíza A, Gomes C, Barbosa J, Mendes K, Souza J De, et al. Educação em saúde no controle da tuberculose: perspectiva de profissionais da estratégia Saúde da Família. Rev Eletrônica Enferm. 2013;15(1):103-12.

31. Almeida ÂS, Lima SVMA, Diniz FS, Silva CC da, Ribeiro CJN, Santos PL dos, et al. Nurses ' Knowledge of The Family Health Strategy on Tuberculosis. J Nurs [Internet]. 2018;12(11):2994-3000. Available from: https://doi.org/10.5205/1981-8963-v12i11a235890p2994-3000-2018 